\title{
The Role of Vitamin K in CKD-MBD
}

\author{
Maria Fusaro ${ }^{1,2}$ (1) . Francesco Tondolo ${ }^{3} \cdot$ Lorenzo Gasperoni $^{3} \cdot$ Giovanni Tripepi $^{4} \cdot$ Mario Plebani $^{5} \cdot$ \\ Martina Zaninotto ${ }^{5}$. Thomas L. Nickolas ${ }^{6}$. Markus Ketteler ${ }^{7}$. Andrea Aghi ${ }^{8}$. Cristina Politi ${ }^{4}$. Gaetano La Manna ${ }^{3}$. \\ Maria Luisa Brandi ${ }^{9}$. Serge Ferrari ${ }^{10} \cdot$ Maurizio Gallieni $^{11} \cdot$ Maria Cristina Mereu $^{12}$ - Giuseppe Cianciolo ${ }^{3}$
}

Accepted: 7 December 2021 / Published online: 8 February 2022

(C) The Author(s), under exclusive licence to Springer Science+Business Media, LLC, part of Springer Nature 2022

\begin{abstract}
Purpose of Review We describe the mechanism of action of vitamin K, and its implication in cardiovascular disease, bone fractures, and inflammation to underline its protective role, especially in chronic kidney disease (CKD).

Recent Findings Vitamin K acts as a coenzyme of y-glutamyl carboxylase, transforming undercarboxylated in carboxylated vitamin K-dependent proteins. Furthermore, through the binding of the nuclear steroid and xenobiotic receptor, it activates the expression of genes that encode proteins involved in the maintenance of bone quality and bone remodeling. There are three main types of K vitamers: phylloquinone, menaquinones, and menadione.

Summary CKD patients, for several conditions typical of the disease, are characterized by lower levels of vitamin $\mathrm{K}$ than the general populations, with a resulting higher prevalence of bone fractures, vascular calcifications, and mortality. Therefore, the definition of vitamin $\mathrm{K}$ dosage is an important issue, potentially leading to reduced bone fractures and improved vascular calcifications in the general population and CKD patients.
\end{abstract}

Keywords Vitamin K $\cdot$ Chronic kidney disease $\cdot$ Inflammation $\cdot$ Cardiovascular disease $\cdot$ Bone fractures

\section{Vitamin K Types of Vitamers, Cycle}

The centrality of vitamin K's role has dramatically expanded in recent years thanks to the discovery of vitamin $\mathrm{K}$ involvement in vascular calcifications, cardiovascular, and bone disease. In the last two decades, many articles analyzed vitamin $\mathrm{K}$ effects, both at physiological and therapeutic levels.

This article is part of the Topical Collection on Kidney and Bone

Maria Fusaro

dante.lucia11@gmail.com

1 National Research Council (CNR), Institute of Clinical Physiology (IFC), Via G. Moruzzi 1, 56124 Pisa, Italy

2 Department of Medicine, University of Padova, Via Giustiniani 2, 35128 Padova, Italy

3 Nephrology, Dialysis and Renal Transplant Unit, IRCCS - Azienda Ospedaliero-Universitaria di Bologna, Alma Mater Studiorum University of Bologna, Bologna, Italy

4 CNR-IFC, Clinical Epidemiology of Renal Diseases and Hypertension, Ospedali Riuniti, Reggio Calabria, Italy

5 Laboratory Medicine Unit, Department of Medicine, University of Padua, Padua, Italy
Vitamin $\mathrm{K}$ is part of the fat-soluble vitamins family. It is characterized by the presence of a 2-methyl-1,4naphthoquinone nucleus. Three principal forms (or vitamers) of vitamin $\mathrm{K}$ are known, which are differentiated by the (lipophilic) side chains linked at the 3 positions: phylloquinone or PK (vitamin K1) with a phytyl side chain; menaquinone or $\mathrm{MKn}$ with a variable number of condensed

6 Division of Nephrology, Department of Medicine, Columbia University Irving Medical Center, New York City, NY, USA

7 Department of General Internal Medicine and Nephrology, Robert-Bosch-Krankenhaus, Stuttgart, Germany

8 Department of Medicine, Clinica Medica 1, University of Padua, Padua, Italy

9 Department of Surgery and Translational Medicine, University of Florence, Viale Pieraccini 6, 50139 Florence, Italy

10 Service des Maladies Osseuses, Département de Médecine, HUG, Genève, Switzerland

11 Department of Biomedical and Clinical Sciences 'Luigi Sacco', Università di Milano, 20157 Milano, Italy

12 Indipendent Research, Cagliari, Italy 
isoprenoid units; and menadione (vitamin K3) without chain, it is a synthetic form (Fig. 1) [1]. All vitamers have different food origins: vitamin K1 is more commonly present in green leafy vegetables, while MKn derives from fermented foods and intestinal bacteria such as Bacteroides and Enterobacteria (Fig. 1) [2]. Menaquinone-4 (MK-4), a type of $\mathrm{MKn}$, is the only one not produced by the intestinal bacterial flora. Still, it is converted from PK through a side chain removal mechanism in specific tissues (pancreas, testes, and vessel wall) into an intermediate molecule, such as menadione (vitamin K3) [3]. The latter molecule is converted into MK-4 by liver enzymes. A normal pancreatic function and the presence of bile salts are the key elements to obtain a good absorption of vitamin K, given its lipophilic structure. Furthermore, vitamin $\mathrm{K}$ is transported into plasma by lipoproteins $[4,5]$. Among fat-soluble vitamins, vitamin $\mathrm{K}$ is the one with the lowest serum levels in humans. For this reason, its metabolic recycling helps to maintain adequate sources of vitamin $\mathrm{K}[1]$.

\section{Mechanism of Vitamin K Actions and Status}

The primary mechanism of vitamin $\mathrm{K}$ action is related to its coenzymatic activity. Indeed it is a substrate for the gammaglutamyl carboxylase (GGCX) that, adding $\mathrm{CO}_{2}$ to glutamic acid residues, leads to the active form of different vitamin $\mathrm{K}-$ dependent proteins (VKDPs) [5].

To date, we know seventeen types of VKDPs. Many of them are involved in well-defined biological processes, while for others, such as proline-rich Gla protein 1 and 2 (PRGP1 and PRGP2), transmembrane Gla protein 3 and 4 (TMG3 and TMG4), the function is not fully understood. Among the VKDPs, we can observe a group of this protein involved in the coagulative cascade: coagulation factors II, VII, IX, X, and anticoagulation proteins $\mathrm{C}, \mathrm{S}$, and $\mathrm{Z}$. They are synthesized in the liver and depend on vitamin K1 activity. Other four proteins, activated outside of the liver, such as matrix Gla protein (MGP), osteocalcin (OC) or bone Gla protein (BGP), growth arrest-specific protein 6 (Gas6), and Gla-rich protein (GRP), are implicated in the bone and vascular mineralization. Finally, there are two transmembrane Gla proteins, periostin and periostin-like factor periostin (PLF), that bind integrins, leading to stimulation of cellular adhesion and migrations $[6$, 7].

Among the VKDPs, the principal proteins implicated in the bone and vascular function are (1) MGP, a $10.6 \mathrm{kDa}$ protein synthesized and secreted in the extracellular matrix mainly by vascular smooth muscle cells (VSMCs) and chondrocytes, which specifically exerts the role of calcification inhibitor. To be activated, in addition to the carboxylation process, this protein will have to undergo phosphorylation of three serine

\section{K1 (Phylloquinone)}

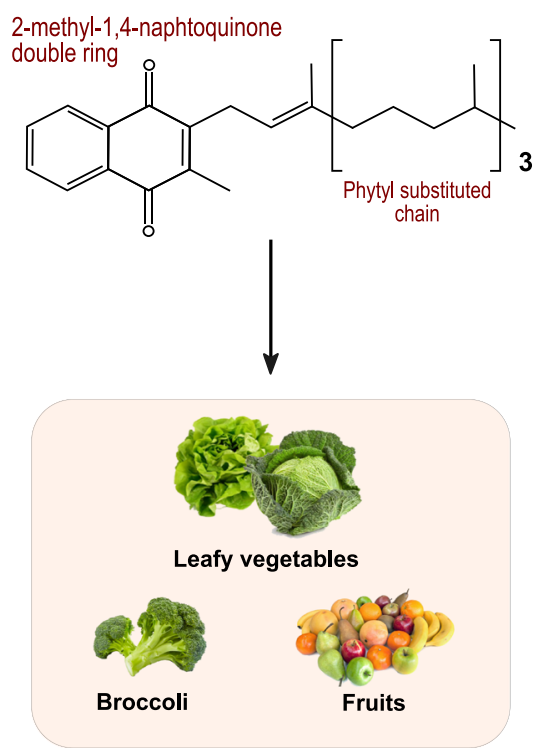

Fig. 1 The sources of vitamin $\mathrm{K}$ are different depending on the vitamers. PK can be found mainly in green leafy vegetables (e.g., kale), vegetables in the Brassica genus (e.g., Brussels sprouts, broccoli), fruits (e.g., avocado, kiwi, and green grapes), herbs (e.g., cilantro, parsley), and green and herbal teas. Other dietary sources are plant oils such as

\section{K3 (Menadione)}<smiles>CC1=CC(=O)c2ccccc2C1=O</smiles>

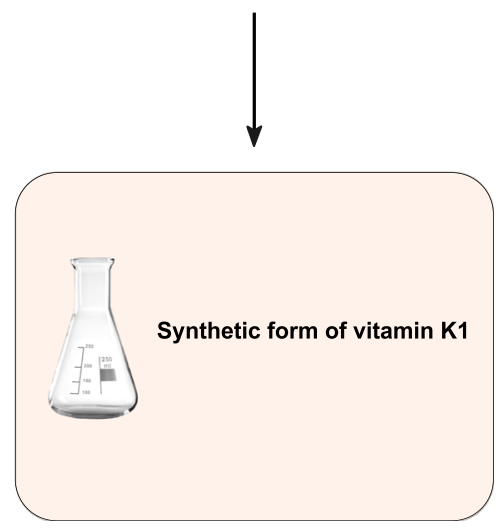

soybean, canola, and olive oils. Fermented foods such as fermented butter or cheese, curdled cheese, egg yolk, and beef liver are sources of MKn. Natto, a traditional Japanese soybean-based food produced by fermentation using Bacillus subtilis, is a source of menaquinone-7 (MK-7) 
sites. Thus, phosphorylation also determines the activity status: p-cMGP: active form; dp-ucMGP: inactive form; (2) OC, which is secreted exclusively in bone by osteoblasts and only a small part of it diffuses in vascular circulation, plays an essential role in the synthesis and regulation of bone matrix, and it is validated as a marker of bone turnover; (3) Gas6, a protein with a molecular weight of $75 \mathrm{kDa}$, has a characteristic function in multiple physiological activities (cellular homeostasis, cell proliferation to cell survival); (4) GRP, involved in the inhibition of articular and cardiovascular calcification and, similarly to MGP, through its ability to bind large amounts of calcium ions by the Gla residues it determines the inhibition of calcium crystal formation [5, 8].

Another important mechanism of vitamin $\mathrm{K}$ action for bone tissue health is the interaction between MK-4 and the steroid and xenobiotic receptor (SXR), which is expressed in several human cells (liver, intestine, and osteoblastic cells). When SXR is activated by its ligand (such as MK-4), it forms a complex with retinoid $\mathrm{X}$ receptor, which binds an SXRresponsive element on the target gene promoter that rules the transcription. With this mechanism, MK-4 induce the expression of genes that encode matrilin-2 (Matn2), tsukushi (Tsk), and CD14 proteins, involved in the maintenance of bone quality (regulating the collagen bone content) and in bone remodeling [7].

The status of carboxylation of the Gla proteins is crucial for bone metabolism and vascular health. It is hypothesized that the deficiency of vitamin $\mathrm{K}$ and their reduced carboxylation may lead both to bone metabolism impairment and increase in vascular calcification. Indeed, when vitamin $\mathrm{K}$ status is deficient, the undercarboxylated (uc) VKDPs are unable to bind calcium ions, thus allowing coagulation factors (protein induced by vitamin K absence II: PIVKA-II), OC, and MGP to interact with negatively charged phospholipid membranes [9].

It follows that the correct dosage of vitamin $\mathrm{K}$ is essential for human health. Unfortunately, the assessment of vitamin $\mathrm{K}$ concentration in plasma is difficult both for the low circulating levels and for non-polar characteristics of vitamin $\mathrm{K}$ and lipid interference. Therefore, there are functional tests that can indirectly indicate the blood levels of vitamin $\mathrm{K}$, such as the prothrombin time (low sensitivity) or measurement of undercarboxylated (uc) proteins, such as OC and MGP (more sensitive for the assessment of subclinical deficit levels) [10, $11]$.

\section{Vitamin $\mathrm{K}$ and Cardiovascular Disease}

As previously pointed out, $\mathrm{CKD}$ patients are exposed to the risk of subclinical vitamin $\mathrm{K}$ deficiency. True deficiency and functional shortage of vitamin $\mathrm{K}$ lead to reduced activation of MGP, a potent inhibitor of tissue calcification, and to the enhancement of vascular inflammation. Therefore, vitamin $\mathrm{K}$ deficiency may contribute to CKD patient's high vascular calcification (VC) burden [7, 12•,13].

Several prospective studies assessed the relationship between circulating vitamin $\mathrm{K}$ status and coronary calcification or incident CVD. Among type 2 diabetes patients, higher dpucMGP levels were associated with incident CVD hazard ratio $[14,15]$.

As a consequence of poor vitamin $\mathrm{K}$ status present in CKD, it is not unexpected that functional vitamin $\mathrm{K}$ deficiency may contribute to high vascular calcification (VC) burden in CKD patients [16].

Active MGP slows the progression of VC in CKD patients by binding hydroxyapatite crystals. This hinders their deposition and promotes macrophage-mediated clearance [17]. Moreover, the interaction between active MGP and bone morphogenetic protein-2 (BMP-2) inhibits VSMC differentiation in osteoblast-like cells, the pivotal step in the development of vascular calcification [18-20].

Some members of the Gla protein family (GRP and MGP) are components of circulating calciprotein particles (CPP) and extracellular vesicles (EVs). Within them, they play an essential role in regulating the calcification process. Circulating CPPs are mainly composed of $\mathrm{Ca}$ and $\mathrm{P}$ precipitates, fetuinA, GRP, and probably MGP. They could contribute to the mechanisms by which ectopic mineralization is prevented. Fetuin, GRP, and other soluble proteins contained in CPPs act like mineral carriers with a role in the stabilization, transport, and recycling of water-insoluble minerals in the blood. A pivotal event in the onset of VSMC calcification is the release of extracellular EVs capable of efficiently nucleating hydroxyapatite in the absence of calcification inhibitors like MGP. Likely, $\gamma$-carboxylated GRP, fetuin-A, and MGP represent an effective pathway that can both regulate the steps of mineral formation and prevent pathological calcification [21].

Krueger et al. hypothesized that undercarboxylated Gla proteins are released to a lesser extent from the cells in an attempt to prevent inactive proteins from entering the tissues. Reduced phosphorylation of the three serine residues of MGP seems equally crucial as it would result in the lower secretion of MGP [22].

The dp-ucMGP (the wholly inactive form of the protein) does not interact with calcium or BMP-2 and closely reflects the vitamin $\mathrm{K}$ status at the vascular wall [23].

Low, rather than high, circulating ucMGP levels are a powerful predictor of cardiovascular calcification, and paradoxically ucMGP serum levels are decreased in CKD patients: this feature could reflect an accumulation of ucMGP within the calcified vessel wall [5, 24-26].

Furthermore, dp-ucMGP levels negatively associate with vitamin $\mathrm{K}$ status, hence decreasing with vitamin $\mathrm{K}$ supplementation and increasing with the use of vitamin $\mathrm{K}$ antagonists [27]. The levels of dp-ucMGP are markedly increased in 
$\mathrm{CKD}$, in a stepwise way to the degree of renal failure [8]. The various circulating MGP forms, including plasma dp-ucMGP, associate with CVD outcomes and vascular calcification in the general population as well as in CKD [28]. Moreover, in CKD patients, the association of dp-ucMGP with VC and CVD mortality was found both in cross-sectional and perspectives studies.

Some studies showed that plasma levels of dp-ucMGP increased progressively with CKD stage and were associated with the severity of vascular calcification [29-31]. On the other hand, although confirming that elevated dp-ucMGP levels largely reflect vitamin $\mathrm{K}$ deficiency, other studies found no correlation with the extent of vascular calcification $[23$, 32].

Finally, three prospective studies, two carried out on CKD patients, and one on kidney transplant recipients (KTRs), found an association of dp-ucMGP with CVD mortality [29, 33, 34] (Table 1).

The use of vitamin $\mathrm{K}$ antagonists (VKAs) represents a model of functional vitamin $\mathrm{K}$ insufficiency, which is added to the pathophysiological and clinical scenario of vitamin $\mathrm{K}$ deficiency of CKD. ESRD can be considered an anticoagulant-like condition. Patients on hemodialysis treated with warfarin had a 3.77 odds ratio of developing severe aortic calcifications compared to those not taking the drug [36]. In a multicenter, cross-sectional study with a 3-year follow-up, Fusaro et al. analyzed data from 387 patients on hemodialysis for $\geq 1$ year. The multivariate logistic regression analyses demonstrated that the use of warfarin was associated with increased odds of aortic and iliac calcifications, prevalence of vertebral fractures, and mortality in warfarin-treated hemodialysis patients [37].

Data from the German calciphylaxis registry and a Japanese survey demonstrated that the treatment with warfarin represents a risk factor for calciphylaxis [38, 39].

The effects of long-term vitamin K supplementation on VC have been evaluated in many randomized controlled trials in nonrenal patients. Although some studies showed a clear benefit of vitamin K on VC, especially with MK4 and MK7 supplementation, others with PK supplementation, failed to reveal any improvement of this outcome parameter [40, 41].

On the contrary, while the effects of the commercially available vitamin $\mathrm{K} 1$ on the carboxylation status of VKDPs in the HD population have not been studied, several dosefinding studies of MK-7 supplementation have been carried out in dialysis patients, disclosing a consistent decrease in the levels of inactive MGP $[42,43]$.

De Vries et al. in a multicenter randomized, controlled trial, analyzed for the first time the effects of vitamin $\mathrm{K}$ status on the progression of $\mathrm{VC}$ in patients on chronic HD. They did not find any difference in the progression of VC over the course of 18 months among patients treated with VKAs, patients in whom the VKA was replaced by rivaroxaban, and patients treated with rivaroxaban that additionally received high-dose vitamin K2 supplements, despite significant differences in dpucMGP levels, considered to be the most accurate marker of vascular vitamin $\mathrm{K}$ status [44]. A more extensive study should confirm the findings by De Vriese et al. before excluding the possibility of favorable effects of new oral anticoagulants (NOACs) and MK-7 supplements on VC. First, although changes from baseline in dp-ucMGP levels over time in the

Table 1 Epidemiological studies and association of vitamin K status with cardiovascular disease and mortality in CKD patients

\begin{tabular}{|c|c|c|c|c|}
\hline Type of study & Design/patients & $\begin{array}{l}\text { Vitamin } K \\
\text { assessment }\end{array}$ & Outcome & Principle results \\
\hline $\begin{array}{l}\text { Cranenburg et al. } \\
\text { TH } 2009 \text { [35] }\end{array}$ & $\begin{array}{l}\text { Cross-sectional } \\
40 \mathrm{CKD}-\mathrm{V}\end{array}$ & ucMGP & CAC score & Inverse correlation \\
\hline $\begin{array}{l}\text { Schurgers et al. } \\
\text { JASN } 2010 \text { [29] }\end{array}$ & $\begin{array}{l}\text { Prospective } \\
107 \text { CKD II-V }\end{array}$ & dp-ucMGP & $\mathrm{AOC}$ & Association with AOC \\
\hline $\begin{array}{l}\text { Thamratnopkoon } \\
\text { Nephron } 2017 \text { [31] }\end{array}$ & $\begin{array}{l}\text { Cross-sectional } \\
83 \text { CKD III-V }\end{array}$ & dp-ucMGP & Kauppila score & $\begin{array}{l}\text { Direct correlation } \\
p=0.004\end{array}$ \\
\hline $\begin{array}{l}\text { Delanaye et al. } \\
\text { BMC Neph2014 [30] }\end{array}$ & $\begin{array}{l}\text { Cross-sectional } \\
160 \mathrm{CKD}-\mathrm{V}\end{array}$ & dp-ucMGP & Kauppila score & $\begin{array}{l}\text { Direct correlation } \\
P=0.0049\end{array}$ \\
\hline $\begin{array}{l}\text { Schlieper et al. } \\
\text { JASN } 2011 \text { [23] }\end{array}$ & $188 \mathrm{CKD}-\mathrm{V}$ & dp-ucMGP & Vascular calcifications & No association \\
\hline $\begin{array}{l}\text { Meuwes et al. } \\
\text { PLoS One } 2015 \text { [32] }\end{array}$ & $\begin{array}{l}\text { Cross-sectional } \\
64.9 \% \text { on dialysis }\end{array}$ & $\begin{array}{l}\text { dp-ucMGP } \\
\text { PIVKA-II }\end{array}$ & CAC score & No association with CAC score \\
\hline $\begin{array}{l}\text { Riphagen et al. } \\
\text { Nutrients } 2017 \text { [34] }\end{array}$ & $\begin{array}{l}\text { Prospective } \\
712 \text { CKD (PREVEND Study) }\end{array}$ & dp-ucMGP & All-cause cardiovascular mortality & Curvilinearly association \\
\hline $\begin{array}{l}\text { Keyzer et al. } \\
\text { Am J Kidney Dis } 2015 \text { [33] }\end{array}$ & $\begin{array}{l}\text { Observational } \\
518 \text { KTRs }\end{array}$ & dp-ucMGP & All-cause mortality and transplant failure & Direct correlation \\
\hline
\end{tabular}

$C K D$, chronic kidney disease; $u c M G P$, uncarboxylated matrix Gla protein; $d p-u c M G P$, plasma dephosphorylated-uncarboxylated matrix Gla protein; $C A C$, coronary artery calcium; $A O C$, aortha calcium score; $K T R s$, kidney transplant recipients 
VKA, rivaroxaban, and rivaroxaban + MK-7 groups were significant, the absolute level of the undercarboxylated protein remained elevated, indicating that functional vitamin $\mathrm{K}$ deficiency might still have been present despite the dose of 2000 mcg thrice weekly. Moreover, the type of administered MK7 is not specified. Third, the study could be underpowered to exclude a protective effect of NOACs and MK-7 supplements.

\section{Vitamin K and Vitamin D in Synergism}

Vitamin D deficiency is common in patients with CKD. Whatever the stage of the disease, it is mainly related to the progressive loss of renal function that involves reduced kidney ability to synthesize active vitamin D. Other reasons for the poor vitamin $\mathrm{D}$ status in CKD patients are the reduced nutritional intake associated with dietary restrictions (e.g., low-protein and low-phosphate diets), tubulointerstitial injury together with inadequate sun exposure linked to decreased mobility.

Vitamin D deficiency is associated with several complications in CKD patients, including infection, endothelial dysfunction, impaired myocardial remodeling, and insulin resistance [45]. Recently, growing evidence is emerging about the synergistic interplay between vitamins $\mathrm{D}$ and $\mathrm{K}$ on both bone and cardiovascular health. Vitamins D and $\mathrm{K}$ share osteoinductive properties.

Since vitamin K-dependent gamma-carboxylation proved to be regulated by vitamin $\mathrm{D}$-binding protein-related gene expression, vitamin D supplementation may be a possible therapeutic target for recovering matrix gammacarboxylation along with vitamin $\mathrm{K}$ [46-50]. Gigante et al. demonstrated that vitamin D3 in association with vitamin MK-7 is able to induce osteogenesis by differentiating human mesenchymal stem cells along the osteoblastic lineage [51].

Vitamin D displays an anabolic effect in bone by increasing osteoblasts activity and by reducing osteoclasts reabsorption. Koshihara et al. showed that both MK-4 and vitamin K1 might stimulate osteoblastogenesis in bone marrow cells and regulate osteoclastogenesis, acting through the expression of receptor activator of nuclear factor kappa_B ligand/osteoclast differentiation factor (RANKL/ODF) [52]. Moreover, in obese/diabetic that a combined treatment with vitamins $\mathrm{K} 2$ and 1,25 (OH) 2 D3 increased in a time-dependently way (7, 14 , and 21 days), the levels of bone anabolic markers and bone formation transcription factors [53].

Transcription and translation of the BGP gene are under the control of 1,25D and PTH [54].

Some studies assessed that menaquinones (MKn) enhance vitamin D3-induced mineralization by increasing BGP gene expression, as well as BGP protein content in the extracellular matrix. BGP has a key role in the synthesis and regulation of bone matrix, in addition to the control bone mineralization [1].
BGP can also carry out a mechanical function within the bone matrix since it binds hydroxyapatite and forms a complex with collagen, acting as a bridge between the matrix and mineral components of bone tissue [55]. Overall, these experimental findings configure a synergistic effect on bone formation and mineralization.

Moreover, vitamin D and vitamin K downregulate inflammatory pathways, in turn, involved not only in osteoporosis but above all, in the progression of vascular calcification [13, 56, 57].

BGP exerts a protective role against vascular calcifications since hemodialysis patients with one or more vertebral fractures have lower serum BGP levels, which are also associated with accelerated abdominal aortic calcification [58].

$1,25(\mathrm{OH}) 2 \mathrm{D}$ upregulates matrix Gla protein (MGP) mRNA and raises MGP secretion several folds. The MGP gene promoter contains a vitamin D response element, enhancing MGP expression after vitamin D binding [59]. MGP expression is also amplified by RANKL, whose synthesis in osteoblastic cells is, in turn, stimulated by 1,25 (OH) 2D through a specific vitamin D-responsive element. Therefore, in addition to being considered one of the most effective endogenous inhibitors of VC, MGP also performs a manifold role in bone turnover since it regulates not only bone formation but also osteoclast differentiation and bone resorption [7].

CKD patients are particularly exposed to the risk of a poor vitamin status (D and $\mathrm{K}$ ). Although all these findings suggest a protective effect in CKD of combined vitamin $\mathrm{D}$ and vitamin $\mathrm{K}$ supplementation in bone and vascular health, no randomized controlled trials examined the effects of such combined treatment in this population. Until now, most studies have evaluated the combined impact of VK and VD supplementation on bone mineral density and bone fractures, mainly in postmenopausal women with osteoporosis [60]. Anyway, no randomized controlled trials examined the effects of combined VD and VK supplementation in CKD patients.

Van Ballegooijen et al. demonstrated that both vitamin D deficiency and vitamin K deficiency were associated with higher systolic and diastolic blood pressure [61]. Asemi et al. showed that synergic supplementation of vitamins D and $\mathrm{K}$ improved insulin sensitivity and carotid intima-medial thickness in type 2 diabetic patients [62]. Only a crosssectional study performed on HD patients demonstrated that treatment with vitamin $\mathrm{D}$ analogs was associated with a higher percentage of total osteocalcin levels [63].

Further studies are needed to explain the pathways involved by the combined effects of vitamin $\mathrm{D}$ and $\mathrm{K}$ on bone and vascular health, especially in the CKD population.

\section{Vitamin $\mathrm{K}$ and Bone Fractures}

The association between CKD and bone fractures has been analyzed in several studies. 
The second phase of the Dialysis Outcomes and Practice Patterns Study (DOPPS), which has involved 12 countries, indicated an incidence of 8.9 per 1000 patients-years for new hip fractures and 25.6 per 1000 for any new fracture [64]. In an analysis carried out on 9714 incident dialysis patients from the Swedish Renal Registry, fractures are common and affect $9 \%$ of patients starting dialysis [65]. Fusaro et al. demonstrated a high vertebral fracture prevalence (57\%) in 86 dialysis-dependent patients [66]. In this population, hip fractures are also common. Alem and colleagues pointed out a higher risk of hip fractures than in the general population, independently of age and gender [67].

In CKD, the metabolism and the effects of VKDPs on bone remodeling and vascular health fit into the complex scenario of CKD-MBD characterized by changes in mineral metabolism, a high risk of bone fractures, and cardiovascular calcification (Fig. 2).
Some studies have investigated the link between poor vitamin $\mathrm{K}$ status and bone health in CKD patients. Kohlmeier et al. proposed the first demonstration of an independent and close correlation between vitamin $\mathrm{K}$ deficiency and high bone fracture risk in dialysis-dependent patients in 68 hemodialyzed patients. Those without bone fractures had higher phylloquinone and carboxylated osteocalcin serum levels than patients with bone fractures [68]. These results were confirmed in an observational study carried out on 387 prevalent hemodialyzed patients, which found an association between vitamin $\mathrm{K}$ status and vertebral fractures, vascular calcification, and survival. In addition, vitamin $\mathrm{K} 1$ deficiency (defined as vitamin $\mathrm{K} 1$ level lower than $0.21 \mathrm{ng} / \mathrm{mL}$ ) was the strongest predictor of vertebral fractures, whose prevalence was over 50\% [58].

To date, few studies analyzed the issue of vitamin $\mathrm{K}$ deficiency in non-dialysis-dependent CKD patients. In these

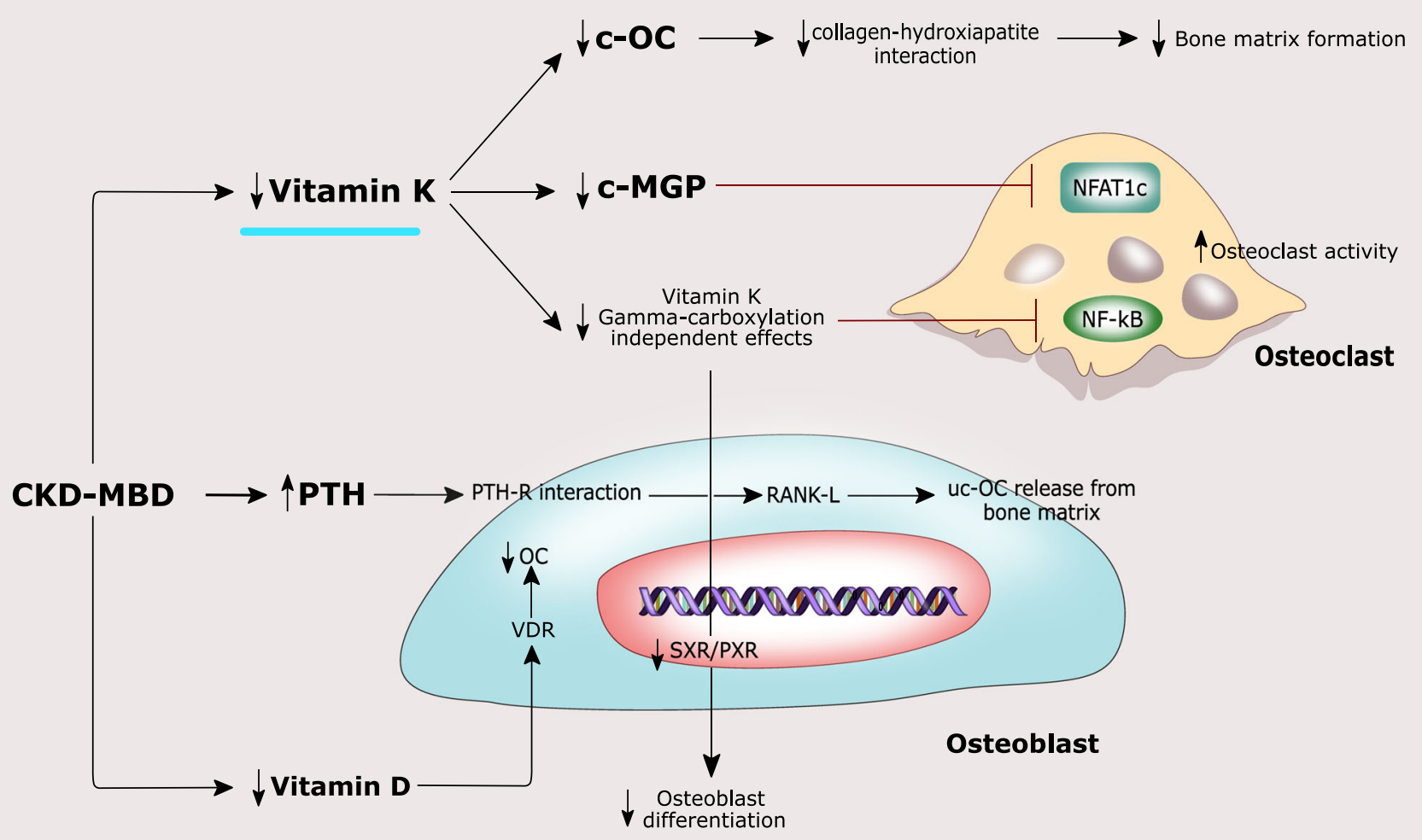

Fig. $2 \mathrm{CKD}$ is characterized by low vitamin $\mathrm{K}$ levels, which in turn lead to reduced MGP and c-OC levels. C-MGP determines a reduction in intracellular calcium flux, causing a decreased NFATc1 activity. Low c-MGP leads to a reduced NFATc1 inhibition with increased osteoclast activity. OC, secreted by osteoblasts, plays an essential role in the synthesis and regulation of the bone matrix. The active carboxylated (cOC) form is mainly involved in bone mineralization allowing the interaction between its calcium-binding Gla residues with hydroxyapatite. OC also acts as an inhibitor of bone mineralization, thus regulating the rate of mineral maturation. Lower vitamin $\mathrm{K}$ levels determine a decrease in SXR/PXR activation and a weaker inhibition of $\mathrm{NK}-\mathrm{kB}$, leading to reduced osteoblast differentiation and increased osteoclast activity, respectively. Elevated PTH levels contribute to bone loss both by activation of RANKL/RANK axis and by the release of ucOC from the bone matrix. In addition, in CKD-MBD, lower vitamin D levels lead to a reduced OC synthesis in osteoblasts through low VDR activation 
patients, Voong et al. showed that subclinical VK deficiency is more frequent with worsening renal function [69]. Evenepoel et al. analyzed 468 adult patients with ESRD referred for a kidney transplant and demonstrated an independent association between vitamin $\mathrm{K}$ status (assessed immediately before transplantation) and bone health. A poor vitamin $\mathrm{K}$ status, defined by dp-ucMGP greater than $500 \mathrm{nmol} / \mathrm{L}$ was independently associated with low aBMD and higher bone incident fractures, while no associations were demonstrated with bone turnover markers [70 ${ }^{\bullet}$.

Several studies identified a poor vitamin K status in KTRs. However, the number of studies that correlate this deficiency with a clinical endpoint (such as bone fractures) is limited [33, $71,72]$.

Some randomized controlled trials addressed the hypothesis of a reduction in fracture risk after vitamin $\mathrm{K}$ administration, specifically the effects of vitamin $\mathrm{K}$ supplementation on fracture risk in the general population [73-75]. In the ECKO trial, 440 postmenopausal women were randomized to either $5 \mathrm{mg}$ of oral vitamin PK or placebo daily for 2 years: in the first group, a lower incidence of clinical fractures was detected [74].

In a smaller study involving 20 patients with chronic glomerulonephritis, Sasaki and colleagues demonstrated the effect of vitamin K supplementation (MK-4) for a year preventing steroid-induced bone loss [76].

The use of warfarin therapy is another crucial variable in the fracture risk profile of dialysis-dependent patients. The mechanism by which warfarin can cause vitamin K deficiency is both direct (inhibition of carboxylation of VKDPs) and indirect (low dietary intake of food rich in vitamin $\mathrm{K}$ ).

We analyzed and compared patients on warfarin treatment for more than 1 year with untreated patients in a crosssectional study with a 3-year follow-up: warfarin-treated male patients had more vertebral fractures than controls $(77.8 \%$ vs. $57.7 \%, p<0.04)$ [37].

Other studies analyzed the action of novel non-vitamin $\mathrm{K}$ antagonist oral anticoagulants (NOACs) on bone health. In an experimental study, dabigatran was compared with warfarin, and the authors demonstrated preservation of femoral and vertebral density and volume in the NOAC treatment group [77]. In three recent clinical trials that compared treatment with VKA versus NOACs for atrial fibrillation on bone health and fracture risks, the authors demonstrated that the use of NOACs was better than VKA in preventing bone fractures [78-80].

\section{Vitamin K Inflammation}

Persistent, low-grade inflammation is a hallmark feature of chronic kidney disease (CKD), involved in CKD progression, vascular disease, and all-cause mortality of these patients [32, $81,82]$.
Furthermore, inflammation is also a major component of other diseases that are independent risk factors for CKD, such as obesity and diabetes [83].

The causes of inflammation in CKD are multifactorial: changes in the mineral metabolism, increased oxidative stress associated with reduced capacity to repair oxidative DNA damage, increased nonenzymatic glycation, intestinal dysbiosis and increased gut permeability, exposure to bacterial endotoxin, biocompatibility issues during dialysis treatment $[84,85]$.

Growing evidence shows that nuclear factor erythroid 2related factor 2 (NRF2)/Kelch-like ECH-associated protein 1 (KEAP1)-dependent antioxidant defense pathway and vitamin $\mathrm{K}$ play a crucial role in counteracting oxidative stress, DNA damage, senescence, and inflammation [86]. These processes are involved in vascular calcification and VSMC differentiation in osteoblast-like cells (Fig. 3) [86].

NRF2 target genes encode several antioxidant proteins such as catalase, heme-oxygenase 1, glutathione peroxidases, $\mathrm{NAD}(\mathrm{P}) \mathrm{H}$ quinone dehydrogenase (NQO1), glutathione Stransferases, peroxiredoxins, thioredoxins, thioredoxin reductases, and glutamate-cysteine ligase (He, Ru and Wen, 2020).

Adaptive activation of NRF2 occurs in response to various inducers in phenotypic remodeling of VSMCs, and numerous agonists of NRF2 signaling have proven to be effective in lowering the pathological VSMC osteogenesis in VC [87]. The anti-inflammatory and antioxidant role of vitamin $\mathrm{K}$ has been traced to both VKDP carboxylation and independent GGCX effects [88].

Vitamin K1 reduces vascular inflammation by antagonizing basal and cytokine-induced activation of the nuclear factor $\kappa \mathrm{B}(\mathrm{NF}-\mathrm{kB})$ in both $\gamma$-carboxylation-independent and dependent pathways [13].

The continuous recycling of vitamin $\mathrm{K}$ is ultimately responsible for antioxidant and anti-inflammatory effects. While VKORC1-like 1 has been found to reduce intracellular oxidative damage [89], $\mathrm{KH} 2$ acts as a strong radical scavenger.

NQO1, one of the antioxidant proteins encoded by an NRF2 target gene, could link NRF2 signaling and the vitamin $\mathrm{K}$ cycle $[87,89,90]$.

Experimental and clinical data also show an inverse association between vitamin $\mathrm{K}$ status and circulating inflammatory markers [91, 92]. Intestinal malabsorption or the administration of drugs (anticoagulant or prolonged antibiotic therapy) inducing vitamin $\mathrm{K}$ deficiency status can increase the levels of inflammatory cytokines, including IL-6 and C-reactive protein [93].

Vitamin K deficiency arising during the early phases of the COVID-19 infection may contribute to the activation of the Th2 storm with increased production of IL-6, which is involved in the building up of the inflammatory response 


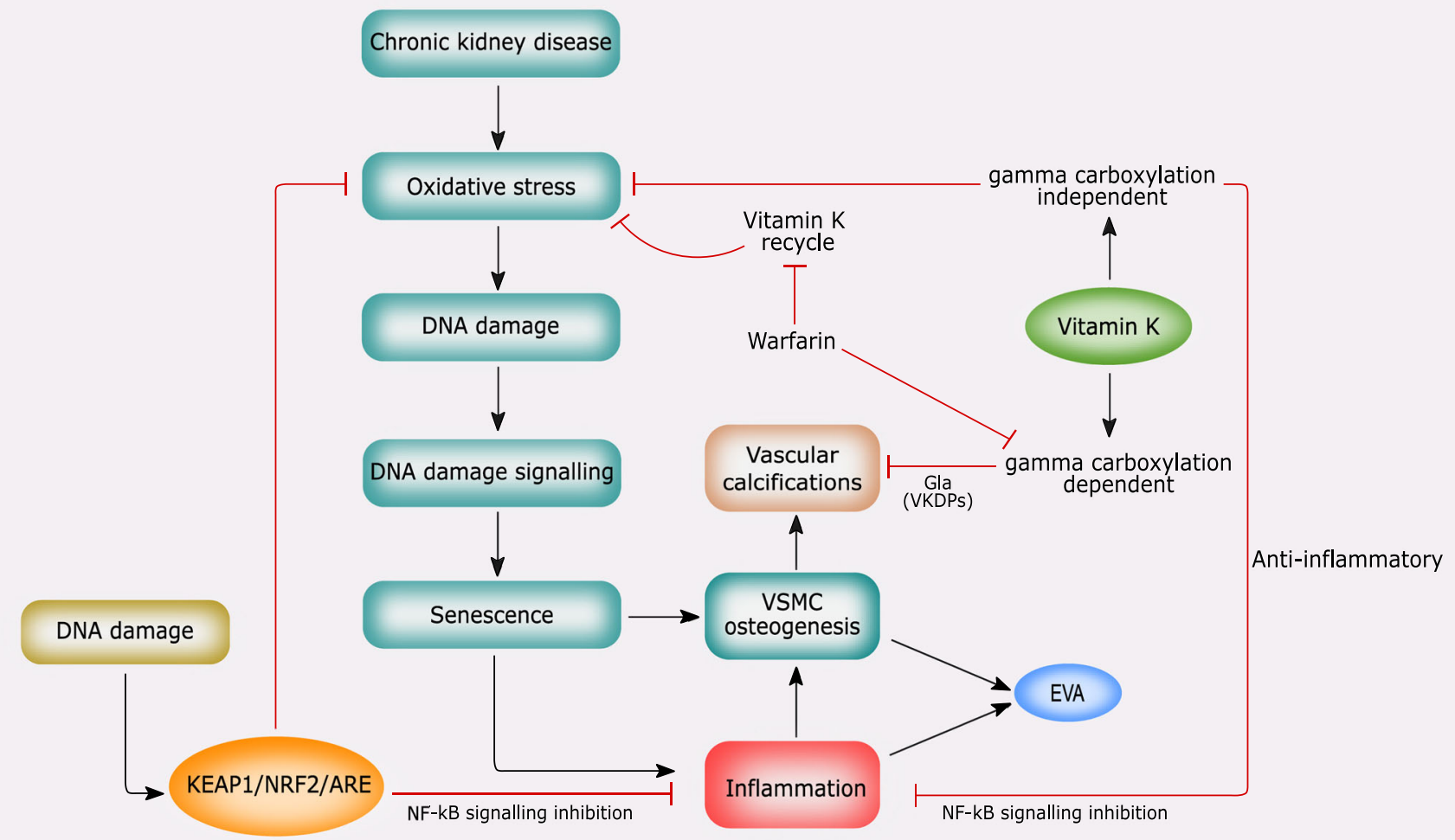

Fig. 3 The role of NRF2 signaling and vitamin K in mediating oxidative stress, DNA damage, senescence, and vascular calcification (see the text for the details)

through the recruitment of both cellular and humoral components [94].

The effects of vitamin K deficiency on the COVID-19 infection take place regardless of its link with inflammation. The active form of vitamin $\mathrm{K}$ is hydroquinone (KH2), produced by a quinone reductase at the expense of NADPH. Following $\gamma$ glutamyl carboxylation, the reduced form of vitamin $\mathrm{K}$ (KH2) is oxidized to vitamin $\mathrm{K}$ 2,3-epoxide (KO). In the so-called vitamin $\mathrm{K}$ cycle, $\mathrm{KH} 2$ is resynthesized by $\mathrm{KO}$ reduction through two reductase activities: vitamin $\mathrm{K}$ epoxide reductase (VKOR), which first transforms KO into K quinone, and then a vitamin $\mathrm{K}$ reductase reduces $\mathrm{K}$ quinone to the $\mathrm{K}$ hydroquinone (KH2) [7].

The rate of vitamin $\mathrm{K}$ recycling depends on a polymorphism in the promoter region of the VKORC1 gene [95].

The VKORC1-1639A allele is associated with low rates of vitamin $\mathrm{K}$ recycling and may be regarded as a natural status analogous to low-dose VKA treatment. Considering the high incidence of VKORC1-1639A in East Asia, this feature may be an explanation for the lower rates of COVID-19 related morbidity and mortality [96]. The increase of dp-ucMGP mediated by vitamin $\mathrm{K}$ insufficiency and derangement of TAM signaling can predispose to thrombosis and disseminate intravascular coagulation, which characterizes the microvascular damage observed in COVID patients [97, 98].

The randomized controlled clinical trial to investigate effects of vitamin K2 in COVID-19 (KOVIT) is an ongoing study designed to evaluate if the improvement of vitamin $\mathrm{K}$ status by vitamin $\mathrm{K}$ supplementation could have favorable effects on pulmonary damage and coagulopathy in COVID19 [99].

\section{CKD-MBD Treatment Effects on Vitamin K Status}

Few studies so far have explored the effects of these longstanding treatments on vitamin $\mathrm{K}$ deficency. This feature is critical when considering that CKD-MBD therapy and vitamin K deficiency act on bone and vascular health.

We carried out a secondary analysis of the VIKI (VItamin $\mathrm{K}$ Italian) study, an observational study designed to assess the prevalence of vitamin $\mathrm{K}$ deficiency in hemodialysis patients and to investigate the effects of ongoing treatment for CKDMBD on OC and MGP levels [58]. We showed that vitamin D analogs increase the levels of OC and MGP, while calcimimetics, alone or combined with calcium acetate, increase only MGP levels. In addition, the combination of 
vitamin $\mathrm{D}$ analogs and calcimimetics proved to be most effective in inducing a further increase of total OC [63].

Equally promising for future developments are the studies that have analyzed the effects of phosphate binders on the absorption and action of vitamin K and VKDP. Studies looking at this issue are still limited, and, most importantly, the results show noticeable differences in the association between various phosphate binders and vitamin $\mathrm{K}$ deficiency. Neradova et al. evaluated the interaction of vitamin K2 (menaquinone-7; MK-7) with five different phosphate binders in the presence or absence of phosphate. In this in vitro study, sucroferric-oxyhydroxide and sevelamer carbonate were the only binders that did not interact with vitamin $\mathrm{K} 2$. Instead, calcium acetate/magnesium carbonate bound vitamin K2 strongly, both in the absence and presence of phosphate. The binding of lanthanum carbonate and vitamin $\mathrm{K} 2$ depended on the absence of phosphate, suggesting a competitive interaction between phosphate and vitamin K2 for this compound [100]. Westenfeld and colleagues analyzed the effect of vitamin K2 supplementation on functional vitamin $\mathrm{K}$ deficiency in $\mathrm{HD}$ patients and did not observe any relationship between sevelamer use and circulating vitamin $\mathrm{K}$ (menaquinone) levels. However, their study was not drawn nor powered to explore this association [42]. In a further analysis of the VIKI study, multivariate logistic regression showed that MK4 deficiency was associated with sevelamer use and aortic calcification [101]. This finding is of considerable importance since low MK4 levels have been recognized as a predictor of aortic calcification [58]. In the same logistic model, sevelamer enhanced the effect of total BGP levels on the odds of vertebral fractures $(\mathrm{OR}=3.15 ; 95 \% \mathrm{CI} 1.46-6.76 ; p=.003)$ in patients with total BGP $<150 \mu \mathrm{g} / \mathrm{L}$ compared to those with total BGP $\geq 150 \mu \mathrm{g} / \mathrm{L}$.

\section{Future Perspectives}

Based on the previous observations, it is possible to evaluate the possibility of introducing vitamin $\mathrm{K}$ supplementation to contrast cardiovascular disease and bone alterations in CKD patients.

In the literature, many ongoing clinical trials and studies analyzed vitamin $\mathrm{K}$ supplementation in CKD patients, both dialysis-dependent and non-dialysis-dependent [7].

One of the most important issues is represented by the definition of vitamin $\mathrm{K}$ dosage able to reduce bone fractures and improve vascular calcifications both in the general population and in CKD patients. A dosage of $10 \mathrm{mg}$ for PK and a $360 \mathrm{mcg} /$ die until over $1080 \mathrm{mcg} / \mathrm{die}$ for MK-7 is considered adequate in CKD patients [7].

The main ongoing trials are reported in Table 2, considering both cardiovascular and bone as primary or secondary outcomes.

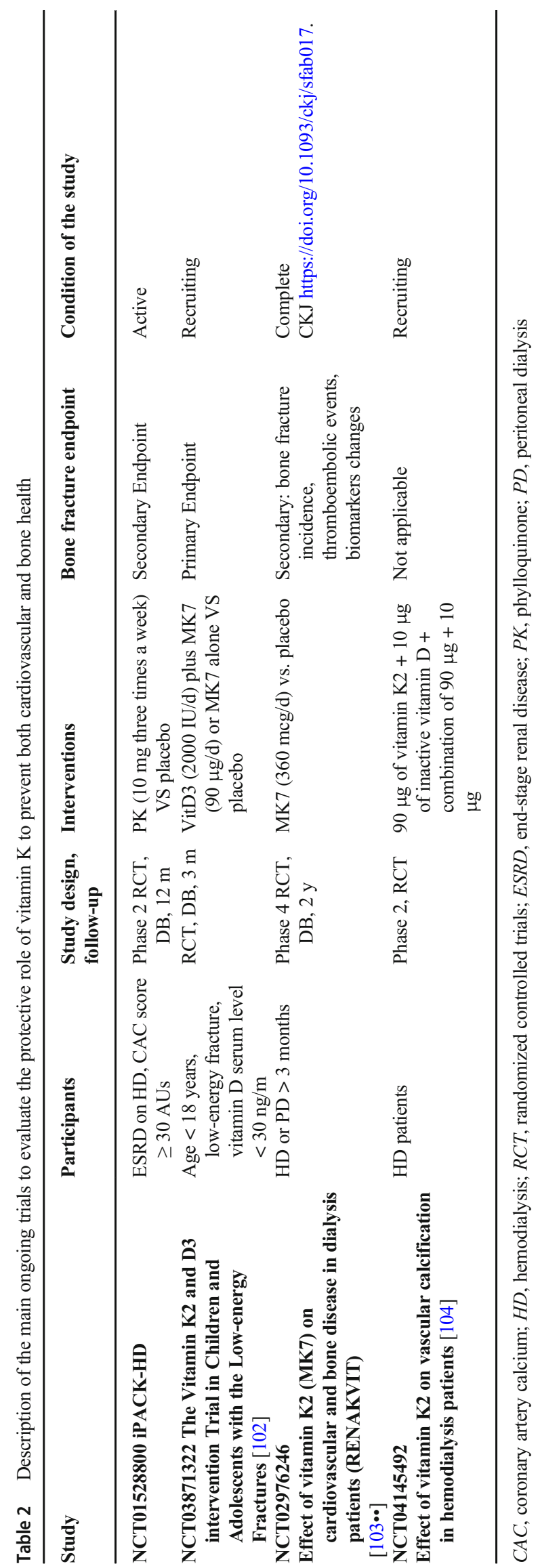




\section{Declarations}

Conflict of Interest Dr. Maria Fusaro, Dr. Francesco Tondolo, Dr Lorenzo Gasperoni, Dr. Giovanni Tripepi, Dr. Mario Plebani, Dr. Martina Zaninotto, Dr. Markus Ketteler, Dr. Andrea Aghi, Dr. Cristina Politi, Dr. Gaetano La Manna, Dr. Maria Cristina Mereu, Dr. Maurizio Gallieni, and Dr. Giuseppe Cianciolo declare no conflict of interest. Dr. Thomas L. Nickolas reports grants from Amgen, other from Pharmacosmos, outside the submitted work. Dr. Maria Luisa Brandi reports other from Amgen, Bruno Farmaceutici, Calcilytix, Kyowa Kirin, UCB, other from Abiogen, Alexion, Amgen, Bruno Farmaceutici, Echolight, Eli Lilly, Kyowa Kirin, SPA, Theramex, UCB, other from Alexion, Amolyt, Bruno Farmaceutici, Calcilytix, Kyowa Kirin, UCB, outside the submitted work. Dr. Serge Ferrari reports grants and other from AMGEN, other from UCB, other from Radius, grants and other from Agnovos, outside the submitted work.

Human and Animal Rights and Informed Consent This article does not contain any studies with human or animal subjects performed by any of the authors

\section{References}

Papers of particular interest, published recently, have been highlighted as:

- Of importance

- Of major importance

1. Fusaro M, Mereu MC, Aghi A, Iervasi G, Gallieni M. Vitamin K and bone. Clin Cases Miner Bone Metab Off J Ital Soc Osteoporos Miner Metab Skelet Dis. 2017;14(2):200-6.

2. Simes DC, Viegas CSB, Araújo N, Marreiros C. Vitamin K as a diet supplement with impact in human health: current evidence in age-related diseases. Nutrients. 3 gennaio 2020;12(1).

3. Walther B, Karl JP, Booth SL, Boyaval P. Menaquinones, bacteria, and the food supply: the relevance of dairy and fermented food products to vitamin $\mathrm{K}$ requirements. Adv Nutr Bethesda Md. 2013;4(4):463-73

4. Cozzolino M, Mangano M, Galassi A, Ciceri P, Messa P, Nigwekar S. Vitamin K in chronic kidney disease. Nutrients. 14 gennaio 2019;11(1)

5. Fusaro M, Gallieni M, Porta C, Nickolas TL, Khairallah P. Vitamin K effects in human health: new insights beyond bone and cardiovascular health. J Nephrol. 2020;33(2):239-49.

6. Wen L, Chen J, Duan L, Li S. Vitamin K-dependent proteins involved in bone and cardiovascular health (Review). Mol Med Rep. 2018;18(1):3-15.

7. Fusaro M, Cianciolo G, Evenepoel P, Schurgers L, Plebani M. Vitamin $\mathrm{K}$ in CKD bone disorders. Calcif Tissue Int. 2021;108(4):476-85.

8. Silaghi CN, Ilyés T, Filip VP, Farcaș M, van Ballegooijen AJ, Crăciun AM. Vitamin $\mathrm{K}$ dependent proteins in kidney disease. Int J Mol Sci. 29 marzo 2019;20(7)

9. Cozzolino M, Cianciolo G, Podestà MA, Ciceri P, Galassi A, Gasperoni L, et al. Current therapy in CKD Patients can affect vitamin K status. Nutrients. 2020;12(6):1609.

10. Caluwé R, F V, As DV. Evaluation of vitamin K status and rationale for vitamin K supplementation in dialysis patients. Nephrol Dial Transplant Off Publ Eur Dial Transpl Assoc - Eur Ren Assoc [Internet]. 1 gennaio 2020 [citato 2 giugno 2021];35(1). Disponibile su: https://pubmed.ncbi.nlm.nih.gov/30590803/
11. Fusaro M, Cosmai L, Evenepoel P, Nickolas TL, Cheung AM, Aghi A, et al. Vitamin K and Kidney transplantation. Nutrients. settembre 2020;12(9):2717.

12. van Ballegooijen AJ, Beulens JW. The Role of Vitamin K status in cardiovascular health: evidence from observational and clinical studies. Curr Nutr Rep. 2017;6(3):197-205. Suggests the role of vitamin $K$ in the vascular calcifications, its deficiency may contribute to high vascular calcification burden in CKD patients.

13. Shioi A, Morioka T, Shoji T, Emoto M. The inhibitory roles of vitamin $\mathrm{K}$ in progression of vascular calcification. Nutrients. febbraio 2020;12(2):583.

14. Dalmeijer GW, van der Schouw YT, Magdeleyns EJ, Vermeer C, Verschuren WMM, Boer JMA, Beulens JWJ. Matrix Gla protein species and risk of cardiovascular events in type 2 diabetic patients. Diabetes Care. 2013;36(11):3766-71.

15. Dalmeijer GW, van der Schouw YT, Magdeleyns EJ, Vermeer C, Verschuren WMM, Boer JMA, Beulens JWJ. Circulating desphospho-uncarboxylated matrix $\gamma$-carboxyglutamate protein and the risk of coronary heart disease and stroke. J Thromb Haemost JTH. 2014;12(7):1028-34.

16. Gallieni M, Fusaro M. Vitamin $\mathrm{K}$ and cardiovascular calcification in CKD: is patient supplementation on the horizon? Kidney Int. 2014;86(2):232-4.

17. Roumeliotis S, Dounousi E, Eleftheriadis T, Liakopoulos V. Association of the inactive circulating matrix Gla protein with vitamin $\mathrm{K}$ intake, calcification, mortality, and cardiovascular disease: a review. Int J Mol Sci. 1 febbraio 2019;20(3).

18. Luo G, Ducy P, McKee MD, Pinero GJ, Loyer E, Behringer RR, et al. Spontaneous calcification of arteries and cartilage in mice lacking matrix GLA protein. Nature. 1997;386(6620):78-81.

19. Schurgers LJ, Cranenburg ECM, Vermeer C. Matrix Gla-protein: the calcification inhibitor in need of vitamin $\mathrm{K}$. Thromb Haemost. 2008;100(4):593-603.

20. Speer MY, Yang H-Y, Brabb T, Leaf E, Look A, Lin W-L, et al. Smooth muscle cells give rise to osteochondrogenic precursors and chondrocytes in calcifying arteries. Circ Res. 27 marzo 2009;104(6):733-41.

21. Viegas CSB, Santos L, Macedo AL, Matos AA, Silva AP, Neves PL, Staes A, Gevaert K, Morais R, Vermeer C, Schurgers L, Simes DC. Chronic kidney disease circulating calciprotein particles and extracellular vesicles promote vascular calcification: a role for GRP (Gla-rich protein). Arterioscler Thromb Vasc Biol. 2018;38(3):575-87.

22. Krueger T, R W, M K, Lj S, J F. Vitamin K deficiency in CKD patients: a modifiable risk factor for vascular calcification? Kidney Int [Internet]. luglio 2009 [citato 2 giugno 2021];76(1). Disponibile su: https://pubmed.ncbi.nlm.nih.gov/19387474/

23. Schlieper G, Westenfeld R, Krüger T, Cranenburg EC, Magdeleyns EJ, Brandenburg VM, Djuric Z, Damjanovic T, Ketteler M, Vermeer C, Dimkovic N, Floege J, Schurgers LJ. Circulating nonphosphorylated carboxylated matrix gla protein predicts survival in ESRD. J Am Soc Nephrol JASN. 2011;22(2):387-95.

24. Hermans MMH, Vermeer C, Kooman JP, Brandenburg V, Ketteler M, Gladziwa U, Rensma PL, Leunissen KML, Schurgers LJ. Undercarboxylated matrix GLA protein levels are decreased in dialysis patients and related to parameters of calcium-phosphate metabolism and aortic augmentation index. Blood Purif. 2007;25(5-6):395-401.

25. Cranenburg ECM, Vermeer C, Koos R, Boumans M-L, Hackeng TM, Bouwman FG, Kwaijtaal M, Brandenburg VM, Ketteler M, Schurgers LJ. The circulating inactive form of matrix Gla Protein (ucMGP) as a biomarker for cardiovascular calcification. J Vasc Res. 2008;45(5):427-36. 
26. Parker BD, Ix JH, Cranenburg ECM, Vermeer C, Whooley MA, Schurgers LJ. Association of kidney function and uncarboxylated matrix Gla protein: data from the Heart and Soul Study. Nephrol Dial Transplant. 1 luglio 2009;24(7):2095-101.

27. Cranenburg ECM, Koos R, Schurgers LJ, Magdeleyns EJ, Schoonbrood THM, Landewé RB, Brandenburg V, Bekers O, Vermeer C. Characterisation and potential diagnostic value of circulating matrix Gla protein (MGP) species. Thromb Haemost. 2010;104(4):811-22.

28. Barrett H, O'Keeffe M, Kavanagh E, Walsh M, O’Connor EM. Is matrix Gla protein associated with vascular calcification? A systematic review. Nutrients. 27 marzo 2018;10(4).

29. Schurgers LJ, Barreto DV, Barreto FC, Liabeuf S, Renard C, Magdeleyns EJ, Vermeer C, Choukroun G, Massy ZA. The circulating inactive form of matrix gla protein is a surrogate marker for vascular calcification in chronic kidney disease: a preliminary report. Clin J Am Soc Nephrol CJASN. 2010;5(4):568-75.

30. Delanaye P, Krzesinski J-M, Warling X, Moonen M, Smelten N, Médart L, et al. Dephosphorylated-uncarboxylated Matrix Gla protein concentration is predictive of vitamin $\mathrm{K}$ status and is correlated with vascular calcification in a cohort of hemodialysis patients. BMC Nephrol. 2014;15:145.

31. Thamratnopkoon S, Susantitaphong P, Tumkosit M, Katavetin P, Tiranathanagul K, Praditpornsilpa K, Eiam-Ong S. Correlations of plasma desphosphorylated uncarboxylated matrix Gla protein with vascular calcification and vascular stiffness in chronic kidney disease. Nephron. 2017;135(3):167-72.

32. Meuwese CL, Olauson H, Qureshi AR, Ripsweden J, Barany P, Vermeer C, et al. Associations between thyroid hormones, calcification inhibitor levels and vascular calcification in end-stage renal disease. PLoS One. 2015;10(7):e0132353.

33. Keyzer CA, Vermeer C, Joosten MM, Knapen MHJ, Drummen NEA, Navis G, Bakker SJL, de Borst MH. Vitamin K status and mortality after kidney transplantation: a cohort study. Am J Kidney Dis Off J Natl Kidney Found. 2015;65(3):474-83.

34. Riphagen IJ, Keyzer CA, Drummen NEA, de Borst MH, Beulens JWJ, Gansevoort RT, et al. Prevalence and effects of functional vitamin k insufficiency: the PREVEND study. Nutrients. 8 dicembre 2017;9(12).

35. Cranenburg ECM, Brandenburg VM, Vermeer C, Stenger M, Mühlenbruch G, Mahnken AH, et al. Uncarboxylated matrix Gla protein (ucMGP) is associated with coronary artery calcification in haemodialysis patients. Thromb Haemost. 2009;101(2): 359-66.

36. Holden RM, Sanfilippo AS, Hopman WM, Zimmerman D, Garland JS, Morton AR. Warfarin and aortic valve calcification in hemodialysis patients. J Nephrol. 2007;20(4):417-22.

37. Fusaro M, Tripepi G, Noale M, Plebani M, Zaninotto M, Piccoli A, Naso A, Miozzo D, Giannini S, Avolio M, Foschi A, Rizzo MA, Gallieni M, Vertebral Fractures And Vascular Calcifications Study Group. Prevalence of vertebral fractures, vascular calcifications, and mortality in warfarin treated hemodialysis patients. Curr Vasc Pharmacol. 2015;13(2):248-58.

38. Brandenburg VM, Cozzolino M, Ketteler M. Calciphylaxis: a still unmet challenge. J Nephrol. 2011;24(2):142-8.

39. Hayashi M, Takamatsu I, Kanno Y, Yoshida T, Abe T, Sato Y, et al. A case-control study of calciphylaxis in Japanese end-stage renal disease patients. Nephrol Dial Transplant Off Publ Eur Dial Transpl Assoc - Eur Ren Assoc. 2012;27(4):1580-4.

40. Shea MK, O'Donnell CJ, Hoffmann U, Dallal GE, DawsonHughes B, Ordovas JM, Price PA, Williamson MK, Booth SL. Vitamin K supplementation and progression of coronary artery calcium in older men and women. Am J Clin Nutr. 2009;89(6): 1799-807.

41. Brandenburg VM, Reinartz S, Kaesler N, Krüger T, Dirrichs T, Kramann $\mathrm{R}$, et al. Slower progress of aortic valve calcification with vitamin $\mathrm{K}$ supplementation: results from a prospective interventional proof-of-concept study. Circulation. 23 maggio 2017;135(21):2081-3.

42. Westenfeld R, Krueger T, Schlieper G, Cranenburg ECM, Magdeleyns EJ, Heidenreich S, Holzmann S, Vermeer C, Jahnen-Dechent W, Ketteler M, Floege J, Schurgers LJ. Effect of vitamin $\mathrm{K} 2$ supplementation on functional vitamin $\mathrm{K}$ deficiency in hemodialysis patients: a randomized trial. Am J Kidney Dis Off J Natl Kidney Found. 2012;59(2):186-95.

43. Caluwé R, Vandecasteele S, Van Vlem B, Vermeer C, De Vriese AS. Vitamin K2 supplementation in haemodialysis patients: a randomized dose-finding study. Nephrol Dial Transplant Off Publ Eur Dial Transpl Assoc - Eur Ren Assoc. 2014;29(7):1385-90.

44. De Vriese AS, Caluwé R, Pyfferoen L, De Bacquer D, De Boeck $\mathrm{K}$, Delanote J, et al. Multicenter Randomized controlled trial of vitamin $\mathrm{K}$ antagonist replacement by rivaroxaban with or without vitamin $\mathrm{K} 2$ in hemodialysis patients with atrial fibrillation: the Valkyrie study. J Am Soc Nephrol JASN. 2020;31(1):186-96.

45. Cianciolo G, Cappuccilli M, Tondolo F, Gasperoni L, Zappulo F, Barbuto S, et al. Vitamin D Effects on Bone Homeostasis and Cardiovascular System in Patients with Chronic Kidney Disease and Renal Transplant Recipients. Nutrients. maggio 2021;13(5): 1453.

46. Lian J, Stewart C, Puchacz E, Mackowiak S, Shalhoub V, Collart D, Zambetti G, Stein G. Structure of the rat osteocalcin gene and regulation of vitamin D-dependent expression. Proc Natl Acad Sci U S A. 1989;86(4):1143-7.

47. Fraser JD, Price PA. Induction of matrix Gla protein synthesis during prolonged 1,25-dihydroxyvitamin D3 treatment of osteosarcoma cells. Calcif Tissue Int. 1990;46(4):270-9.

48. Szulc P, Delmas PD. Influence of vitamin D and retinoids on the gammacarboxylation of osteocalcin in human osteosarcoma MG63 cells. Bone. 1996;19(6):615-20.

49. Miyake N, Hoshi K, Sano Y, Kikuchi K, Tadano K, Koshihara Y. 1,25-dihydroxyvitamin D3 promotes vitamin $\mathrm{K} 2$ metabolism in human osteoblasts. Osteoporos Int. 1 settembre 2001;12(8):680 7.

50. Hou Y-C, Lu C-L, Zheng C-M, Chen R-M, Lin Y-F, Liu W-C, et al. Emerging role of vitamins $\mathrm{D}$ and $\mathrm{K}$ in Modulating uremic vascular calcification: the aspect of passive calcification. Nutrients. gennaio 2019;11(1):152.

51. Gigante A, F B, S C, S M, Gp L, L T. Vitamin MK-7 enhances vitamin D3-induced osteogenesis in hMSCs: modulation of key effectors in mineralization and vascularization. J Tissue Eng Regen Med [Internet]. giugno 2015 [citato 2 giugno 2021];9(6). Disponibile su: https://pubmed.ncbi.nlm.nih.gov/23109511/

52. Koshihara Y, Hoshi K, Okawara R, Ishibashi H, Yamamoto S. Vitamin K stimulates osteoblastogenesis and inhibits osteoclastogenesis in human bone marrow cell culture. J Endocrinol. 2003;176(3):339-48.

53. Poon CCW, Li RWS, Seto SW, Kong SK, Ho HP, Hoi MPM, et al. In vitro vitamin $\mathrm{K}(2)$ and $1 \alpha, 25$-dihydroxyvitamin $\mathrm{D}(3)$ combination enhances osteoblasts anabolism of diabetic mice. Eur J Pharmacol. 2015;767:30-40.

54. Carvallo L, Henríquez B, Paredes R, Olate J, Onate S, van Wijnen AJ, Lian JB, Stein GS, Stein JL, Montecino M. 1alpha,25-dihydroxy vitamin D3-enhanced expression of the osteocalcin gene involves increased promoter occupancy of basal transcription regulators and gradual recruitment of the 1alpha,25-dihydroxy vitamin D3 receptor-SRC-1 coactivator complex. J Cell Physiol. 2008;214(3):740-9.

55. Ritter NM, Farach-Carson MC, Butler WT. Evidence for the formation of a complex between osteopontin and osteocalcin. J Bone Miner Res Off J Am Soc Bone Miner Res. 1992;7(8):877-85. 
56. van Etten E, Mathieu C. Immunoregulation by 1,25-dihydroxyvitamin D3: basic concepts. J Steroid Biochem Mol Biol. 2005;97(1-2):93-101.

57. Mazzaferro S, Cianciolo G, De Pascalis A, Guglielmo C, Urena Torres PA, Bover J, et al. Bone, inflammation and the bone marrow niche in chronic kidney disease: what do we know? Nephrol Dial Transplant Off Publ Eur Dial Transpl Assoc - Eur Ren Assoc. 1 dicembre 2018;33(12):2092-100.

58. Fusaro M, Noale M, Viola V, Galli F, Tripepi G, Vajente N, Plebani M, Zaninotto M, Guglielmi G, Miotto D, Dalle Carbonare L, D'Angelo A, Naso A, Grimaldi C, Miozzo D, Giannini S, Gallieni M, for the VItamin K Italian (VIKI) Dialysis Study Investigators. Vitamin K, vertebral fractures, vascular calcifications, and mortality: VItamin K Italian (VIKI) dialysis study. J Bone Miner Res Off J Am Soc Bone Miner Res. 2012;27(11):2271-8.

59. van Ballegooijen AJ, Beulens JWJ, Schurgers LJ, de Koning EJ, Lips P, van Schoor NM, et al. Effect of 6-month vitamin D supplementation on plasma matrix Gla protein in older adults. Nutrients. febbraio 2019;11(2):231.

60. Ziemińska M, Sieklucka B, Pawlak K. Vitamin K and D Supplementation and bone health in chronic kidney diseaseapart or together? Nutrients. 2021;13(3).

61. van Ballegooijen AJ, Cepelis A, Visser M, Brouwer IA, van Schoor NM, Beulens JW. Joint association of low vitamin D and vitamin K Status with blood pressure and hypertension. Hypertens Dallas Tex 1979. 2017;69(6):1165-72.

62. Asemi Z, Raygan F, Bahmani F, Rezavandi Z, Talari HR, Rafiee M, Poladchang S, Darooghegi Mofrad M, Taheri S, Mohammadi AA, Esmaillzadeh A. The effects of vitamin D, K and calcium cosupplementation on carotid intima-media thickness and metabolic status in overweight type 2 diabetic patients with CHD. Br J Nutr. 2016;116(2):286-93.

63. Fusaro M, Giannini S, Gallieni M, Noale M, Tripepi G, Rossini M, Messa P, Rigotti P, Pati T, Barbisoni F, Piccoli A, Aghi A, Alessi M, Bonfante L, Fabris F, Zambon S, Sella S, Iervasi G, Plebani M. Calcimimetic and vitamin D analog use in hemodialyzed patients is associated with increased levels of vitamin K dependent proteins. Endocrine. 2016;51(2):333-41.

64. Jadoul M, Albert JM, Akiba T, Akizawa T, Arab L, BraggGresham JL, Mason N, Prutz KG, Young EW, Pisoni RL. Incidence and risk factors for hip or other bone fractures among hemodialysis patients in the Dialysis Outcomes and Practice Patterns Study. Kidney Int. 2006;70(7):1358-66.

65. Iseri K, Carrero JJ, Evans M, Felländer-Tsai L, Berg H, Runesson B, Stenvinkel P, Lindholm B, Qureshi AR. Major fractures after initiation of dialysis: incidence, predictors and association with mortality. Bone. 2020;133:115242.

66. Fusaro M, Crepaldi G, Maggi S, Galli F, D’Angelo A, Calò L, Giannini S, Miozzo D, Gallieni M. Vitamin K, bone fractures, and vascular calcifications in chronic kidney disease: an important but poorly studied relationship. J Endocrinol Investig. 2011;34(4): $317-23$.

67. Alem AM, Sherrard DJ, Gillen DL, Weiss NS, Beresford SA, Heckbert SR, Wong C, Stehman-Breen C. Increased risk of hip fracture among patients with end-stage renal disease. Kidney Int. 2000;58(1):396-9.

68. Kohlmeier M, Saupe J, Shearer MJ, Schaefer K, Asmus G. Bone health of adult hemodialysis patients is related to vitamin $\mathrm{K}$ status. Kidney Int. 1997;51(4):1218-21.

69. Voong K, Harrington D, Goldsmith D. Vitamin K status in chronic kidney disease: a report of a study and a mini-review. Int Urol Nephrol. 2013;45(5):1339-44.

70. Evenepoel P, Claes K, Meijers B, Laurent M, Bammens B, Naesens M, et al. Poor vitamin K status is associated with low bone mineral density and increased fracture risk in end-stage renal disease. J Bone Miner Res Off J Am Soc Bone Miner Res. 2019;34(2):262-9 The authors considered the association of the vitamin $K$ with important clinical outcomes such as vascular calcifications and bone fractures and they demonstrate an independent association between vitamin $K$ status (assessed immediately before transplantation) and bone health.

71. Boxma PY, van den Berg E, Geleijnse JM, Laverman GD, Schurgers LJ, Vermeer C, Kema IP, Muskiet FA, Navis G, Bakker SJL, de Borst MH. Vitamin k intake and plasma desphospho-uncarboxylated matrix Gla-protein levels in kidney transplant recipients. PLoS One. 2012;7(10):e47991.

72. Jansz TT, Neradova A, van Ballegooijen AJ, Verhaar MC, Vervloet MG, Schurgers LJ, van Jaarsveld BC. The role of kidney transplantation and phosphate binder use in vitamin $\mathrm{K}$ status. PLoS One. 2018;13(8):e0203157.

73. Shiraki M, Shiraki Y, Aoki C, Miura M. Vitamin K2 (menatetrenone) effectively prevents fractures and sustains lumbar bone mineral density in osteoporosis. J Bone Miner Res Off J Am Soc Bone Miner Res. 2000;15(3):515-21.

74. Cheung AM, Tile L, Lee Y, Tomlinson G, Hawker G, Scher J, et al. Vitamin K supplementation in postmenopausal women with osteopenia (ECKO trial): a randomized controlled trial. PLoS Med. 14 ottobre 2008;5(10):e196.

75. Knapen MHJ, Drummen NE, Smit E, Vermeer C, Theuwissen E. Three-year low-dose menaquinone-7 supplementation helps decrease bone loss in healthy postmenopausal women. Osteoporos Int J Establ Result Coop Eur Found Osteoporos Natl Osteoporos Found USA. 2013;24(9):2499-507.

76. Sasaki N, Kusano E, Takahashi H, Ando Y, Yano K, Tsuda E, Asano Y. Vitamin K2 inhibits glucocorticoid-induced bone loss partly by preventing the reduction of osteoprotegerin (OPG). J Bone Miner Metab. 2005;23(1):41-7.

77. Fusaro M, Dalle Carbonare L, Dusso A, Arcidiacono MV, Valenti MT, Aghi A, Pasho S, Gallieni M. Differential effects of dabigatran and warfarin on bone volume and structure in rats with normal renal function. PLoS One. 2015;10(8):e0133847.

78. Binding C, Bjerring Olesen J, Abrahamsen B, Staerk L, Gislason $\mathrm{G}$, Nissen Bonde A. Osteoporotic fractures in patients with atrial fibrillation treated with conventional versus direct anticoagulants. J Am Coll Cardiol. 29 ottobre 2019;74(17):2150-8.

79. Huang H-K, Liu PP-S, Hsu J-Y, Lin S-M, Peng CC-H, Wang J-H, et al. Fracture risks among patients with atrial fibrillation receiving different oral anticoagulants: a real-world nationwide cohort study. Eur Heart J. 7 marzo 2020;41(10):1100-8.

80. Lutsey PL, Norby FL, Ensrud KE, MacLehose RF, Diem SJ, Chen LY, et al. Association of anticoagulant therapy with risk of fracture among patients with atrial fibrillation. JAMA Intern Med. 1 febbraio 2020;180(2):245-53.

81. Menon V, Greene T, Wang X, Pereira AA, Marcovina SM, Beck GJ, et al. C-reactive protein and albumin as predictors of all-cause and cardiovascular mortality in chronic kidney disease. Kidney Int. 2005;68(2):766-72.

82. Ebert T, Pawelzik S-C, Witasp A, Arefin S, Hobson S, Kublickiene $\mathrm{K}$, et al. Inflammation and premature ageing in chronic kidney disease. Toxins. 4 aprile 2020;12(4).

83. Wu H, Ballantyne CM. Metabolic inflammation and insulin resistance in obesity. Circ Res. 22 maggio 2020;126(11):1549-64.

84. Carrero JJ, Stenvinkel P. Persistent inflammation as a catalyst for other risk factors in chronic kidney disease: a hypothesis proposal. Clin J Am Soc Nephrol. 1 dicembre 2009;4(Supplement 1):S49 55.

85. Ruiz S, Pergola PE, Zager RA, Vaziri ND. Targeting the transcription factor Nrf2 to ameliorate oxidative stress and inflammation in chronic kidney disease. Kidney Int. 2013;83(6):1029-41. 
86. Dai L, Schurgers LJ, Shiels PG, Stenvinkel P. Early vascular ageing in chronic kidney disease: impact of inflammation, vitamin K, senescence and genomic damage. Nephrol Dial Transplant Off Publ Eur Dial Transpl Assoc - Eur Ren Assoc. 1 marzo 2020;35(Suppl 2):ii31-7.

87. Wei R, Enaka M, Muragaki Y. Activation of KEAP1/NRF2/P62 signaling alleviates high phosphate-induced calcification of vascular smooth muscle cells by suppressing reactive oxygen species production. Sci Rep. 17 luglio 2019;9(1):10366.

88. Ohsaki Y, Shirakawa H, Hiwatashi K, Furukawa Y, Mizutani T, Komai M. Vitamin K suppresses lipopolysaccharide-induced inflammation in the rat. Biosci Biotechnol Biochem. 2006;70(4): 926-32.

89. Westhofen P, Watzka M, Marinova M, Hass M, Kirfel G, Müller J, et al. Human vitamin K 2,3-epoxide reductase complex subunit 1-like 1 (VKORC1L1) mediates vitamin K-dependent intracellular antioxidant function *. J Biol Chem. 29 aprile 2011;286(17): 15085-94.

90. Mukai K, Itoh S, Morimoto H. Stopped-flow kinetic study of vitamin $\mathrm{E}$ regeneration reaction with biological hydroquinones (reduced forms of ubiquinone, vitamin $\mathrm{K}$, and tocopherolquinone) in solution. J Biol Chem. 5 novembre 1992;267(31):22277-81.

91. Shea MK, Booth SL, Massaro JM, Jacques PF, D'Agostino RB, Dawson-Hughes B, et al. Vitamin K and vitamin D status: associations with inflammatory markers in the Framingham Offspring Study. Am J Epidemiol. 1 febbraio 2008;167(3):313-20.

92. Shea MK, Cushman M, Booth SL, Burke GL, Chen H, Kritchevsky SB. Associations between vitamin K status and haemostatic and inflammatory biomarkers in communitydwelling adults: the Multi-Ethnic Study of Atherosclerosis. Thromb Haemost. 2 settembre 2014;112(3):438-44.

93. Harshman SG, Shea MK. The role of vitamin K in chronic aging diseases: inflammation, cardiovascular disease, and osteoarthritis. Curr Nutr Rep. 2016;5(2):90-8.

94. Anastasi E, Ialongo C, Labriola R, Ferraguti G, Lucarelli M, Angeloni A. Vitamin K deficiency and covid-19. Scand J Clin Lab Invest. 2 novembre 2020;80(7):525-7.

95. Garcia AA, Reitsma PH. VKORC1 and the vitamin K cycle. Vitam Horm. 2008;78:23-33.

96. Janssen R, Walk J. Vitamin K epoxide reductase complex subunit 1 (VKORC1) gene polymorphism as determinant of differences in Covid-19-related disease severity. Med Hypotheses. 2020;144: 110218.

97. Dofferhoff ASM, Piscaer I, Schurgers LJ, Visser MPJ, van den Ouweland JMW, de Jong PA, et al. Reduced vitamin K status as a potentially modifiable risk factor of severe COVID-19. Clin Infect Dis Off Publ Infect Dis Soc Am. 27 agosto 2020;
98. Tutusaus A, Marí M, Ortiz-Pérez JT, Nicolaes GAF, Morales A, García de Frutos P. Role of vitamin K-dependent factors protein $\mathrm{S}$ and GAS6 and TAM receptors in SARS-CoV-2 infection and COVID-19-associated immunothrombosis. Cells. 28 settembre 2020;9(10).

99. Dofferhoff T. A phase 2, double blind, randomized, placebocontrolled clinical trial to investigate the safety and effects of oral vitamin K2 supplementation in COVID-19 [Internet]. clinicaltrials.gov; 2021 feb [citato 2 giugno 2021]. Report No.: NCT04770740. Disponibile su. https://clinicaltrials.gov/ct2/ show/NCT04770740.

100. Neradova A, Schumacher SP, Hubeek I, Lux P, Schurgers LJ, Vervloet MG. Phosphate binders affect vitamin K concentration by undesired binding, an in vitro study. BMC Nephrol 2 maggio. 2017;18(1):149.

101. Fusaro M, Cozzolino M, Plebani M, Iervasi G, Ketteler M, Gallieni M, Aghi A, Locatelli F, Cunningham J, Salam S, Zaninotto M, Ravera M, Russo D, Mereu MC, Giannini S, Brandi ML, Ferrari S, Sella S, Egan CG, et al. Sevelamer Use, vitamin $\mathrm{K}$ levels, vascular calcifications, and vertebral fractures in hemodialysis patients: results from the VIKI study. J Bone Miner Res. 2021;36(3):500-9.

102. Medical University of Bialystok. Rationale and Design of the vitamin $\mathrm{K} 2$ and vitamin D3 intervention trial in children and adolescents with the low-energy bone fractures [Internet]. clinicaltrials.gov; 2021 mar [citato 2 giugno 2021]. Report No.: NCT03871322. Disponibile su: https://clinicaltrials.gov/ct2/ show/NCT03871322

103.• Levy-Schousboe K, Frimodt-Møller M, Hansen D, Peters CD, Kjærgaard KD, Jensen JD, et al. Vitamin K supplementation and arterial calcification in dialysis: results of the double-blind, randomized, placebo-controlled RenaKvit trial. Clin Kidney J [Internet]. 28 gennaio 2021 [citato 3 giugno 2021];(sfab017). Disponibile su: https://doi.org/10.1093/ckj/sfab017. This trial underlines the protective effect of vitamin K2 (MK7) on cardiovascular and bone disease in dialysis patients.

104. Borolossy RMAEKE. The Impact of Vitamin K2 and inactive vitamin D supplementation on vascular calcification in pediatric patients on regular hemodialysis [Internet]. clinicaltrials.gov; 2019 ott [citato 2 giugno 2021]. Report No.: NCT04145492. Disponibile su: https://clinicaltrials.gov/ct2/show/NCT04145492. 2021.

Publisher's Note Springer Nature remains neutral with regard to jurisdictional claims in published maps and institutional affiliations. 